\title{
Advances in diagnostic and treatment options in patients with fibromyalgia syndrome
}

This article was published in the following Dove Press journal:

Open Access Rheumatology Research and Reviews

9 December 2009

Number of times this article has been viewed

\author{
Ali Gur' \\ Pelin Oktayoglu ${ }^{2}$ \\ 'Department of Physical Medicine \\ and Rehabilitation, Medical Faculty, \\ Gaziantep University, Gaziantep, \\ Turkey; ${ }^{2}$ Department of Physical \\ Medicine and Rehabilitation, Batman \\ State Hospital, Batman, Turkey
}

\begin{abstract}
Fibromyalgia (FM) is characterized as a chronic, painful, noninflammatory syndrome affecting the musculoskeletal system. In addition to pain, common co-morbid symptoms associated with FM include sleep disturbances, fatigue, morning stiffness, affective disorders, chronic daily headache, dyscognition, irritable bowel syndrome, and irritable bladder. Fibromyalgia is usually classified by application of the American College of Rheumatology (ACR) criteria. Although these criteria are accepted among investigators who agree with the concept of fibromyalgia, they do so with some reservations. Tender points and widespread pain alone does not describe the esence of fibromyalgia. New diagnostic tools including either clinical or radiological components are studied to diminish these problems. Although various pharmacological solutions have been studied for treating fibromyalgia, no single drug or groups of drugs have proved to be useful in treating fibromyalgia patients. Recently, three drugs, pregabalin, duloxetine and milnacipran, were approved for the treatment of FM by the US Food and Drug Administration (FDA). Novel therapeutic approaches to the management of FM include cannabinoids, sodium channel blockade and new generation antiepileptics. This review evaluates both new diagnostic tools, including clinical or radiological regimes, and tries to highlight the efficacy of medicinal and nonmedicinal treatments with new therapeutic approaches in the management of FM with a wide perspective.
\end{abstract}

Keywords: diagnosis, fibromyalgia, rehabilitation, treatment

\section{Introduction}

Fibromyalgia (FM) is a chronic, musculoskeletal pain condition associated with some co-morbid symptoms. The American College of Rheumatology (ACR) recommends that patients meet two specific criteria in the diagnosis of FM; a history of widespread pain for at least three months and pain in 11 of 18 specific anatomical sites described as tender points on digital palpation with an approximate force of $40 \mathrm{~N}$ (equivalent to $4 \mathrm{~kg}$ weight force) for classification of FM. ${ }^{1}$ This definition, however, does not include the large number of other symptoms associated with fibromyalgia, including fatigue, nonrestorative sleep, morning stiffness, headache, cognitive disturbances, anxiety, and parasthesias. Depressive syptoms are also quite common in FM patients. ${ }^{2}$

ACR criteria are accepted among investigators who are in agreement with the concept of fibromyalgia, although with some reservations. In practice the diagnosis is often made without the formal tender point examination. Although patients may have the required number of appropriate tender points and these tender points are widespread, pain alone is insufficient to diagnose fibromyalgia. ${ }^{3,4}$ In a series of focus groups, clinical experts and patients agreed that while pain is an important symptom of FM, it is also
Correspondence: Ali Gur Department of Physical Medicine and Rehabilitation, Medical Faculty, Gaziantep University, Gaziantep, Turkey Tel +90342360 6060 Ext. 76220

Fax +90342360 6223

Email aligur70@hotmail.com 
necessary to assess other co-morbid symptoms as mentioned above. ${ }^{5}$ Despite extensive clinical study, there is no distinct consensus on the optimal management of FM. Previous guidelines for the management of fibromyalgia recommended an approach that integrates pharmacological and nonpharmacological therapies, selected according to the symptoms experienced by individual patients. Therefore, assessing the effectiveness of new therapies requires accurate documentation of a multidimensional array of clinical manifestations. This review analyzes the problems associated with ACR classification criteria for FM and presents new diagnostic methods related with this syndrome. We also evaluate the medicinal and nonmedicinal treatments with new therapeutic approaches in FM with a wide perspective. Articles were identified in the PubMed database by using the following search terms, alone or in combination: "fibromyalgia", "new therapies", "diagnosing methods", "treatment". No date restriction was placed on the search. Original articles from the bibliographies of these primary articles were also reviewed.

\section{Fibromyalgia syndrome} Clinical features

FM is characterized as a chronic, painful, noninflammatory syndrome affecting the musculoskeletal system. This disease affects $2 \%$ of the population: $0.5 \%$ of men and $3.4 \%$ of women. ${ }^{6}$ The etiology and pathophysiology of the disease remains unclear. Current hypotheses center on atypical sensory processing in the CNS and dysfunction of skeletal muscle nociception and the hypothalamic-pituitary-adrenal (HPA) axis. ${ }^{7}$ Patients seem to have a generalized abnormality in pain perception, with a decline in pain threshold and tolerance to an assortment of stimuli, such as pressure, cold, and heat. ${ }^{8}$ In addition to pain, common co-morbid symptoms associated with FM include sleep disturbances, fatigue, morning stiffness, affective disorders, chronic daily headache, dyscognition, irritable bowel syndrome, and irritable bladder. ${ }^{6}$

\section{Pathogenesis}

\section{Central sensitization and windup}

It was suggested that the pathogenesis of FM involves aberrations in central nervous system (CNS) function that result in abnormal pain perception. ${ }^{9}$ Central sensitization of nociceptive neurons in the dorsal horn that are due to activation of N-methyl-D-aspartic acid (NMDA) receptors and disinhibition of pain, that is a result of deficient function of the descending inhibitory system, are probably pathogenic factors for hypersensitivity to all kind of stimuli. ${ }^{10}$
In a another definition central sensitization is described as hyperexcitability of the CNS neurons in response to peripheral noxious stimuli, coressponding to an exaggerated response to normally painful stimulus (hyperalgesia), increased duration of response following a brief stimulus (persistent pain) and a response of pain following a normally nonnociceptive stimulus, for example, touch or rubbing (allodynia). ${ }^{11}$ One of the hypothesis that hyperalgesia in patients with FM is due to an upregulation in the central nociceptive system. ${ }^{12}$

Important CNS mechanisms relevant for FM pain include temporal summation of pain (windup) and central sensitization. ${ }^{13,14}$ Windup (WU) represents an important pain mechanism that can result in both short and long-term changes of neuronal responsiveness, including central sensitization. WU occurs during repetitive nociceptive stimuli of sufficient intensity or frequency to remove the magnesium block of the NMDA receptor. This event is followed by calcium influx into the cell and subsequent triggering of signaling cascades that can result in amplification of nociceptive input and long-term central sensitization. Importantly, once central sensitization has occurred only minimal nociceptive input is required to maintain the sensitized state and clinical pain. Many studies have indicated evidence for abnormal WU and central sensitization in patients with FM. ${ }^{15,16}$ It is therefore conceivable that acute or chronic triggers such as trauma or infections can result in the chronic widespread pain of FM. ${ }^{13,17}$

\section{Diagnosing of FM}

In the late 1980s, the Fibromyalgia Multicenter Criteria Committee was formed under the auspices of the American College of Rheumatology. Its classification criteria, adopted in 1990, provided a starting point from which to standardize the study of patients with this condition. ${ }^{1}$ The publication of the ACR criteria was a great step forward in the understanding of the syndrome.

According to the ACR's criteria; FM is defined as widespread pain of at least three months duration and pain on palpation of at least 11 of 18 specific tender sites on the body. The dual criteria of widespread pain and tender points results in $88.4 \%$ sensitivity and $81.1 \%$ specificity for diagnosing FM. ${ }^{1}$ There are, however, limitations to the ACR diagnostic criteria. They are entirely subjective and qualitative, centering on the patient's report of pain and the physician's interpretation of behaviors related to pain, such as withdrawing from the stimulus, grimacing, or crying. ${ }^{18}$ Improved methods that present stimuli in a random, unpredictable fashion (for example, multiple random staircase) tend to minimize the 
influence of these factors. ${ }^{19}$ There is no viable method to blind either the subject or the examiner.

Another significant problem with the ACR criteria is the diagnostic method regarding the palpation of the 18 points $^{20}$ with a finger pressure of "approximately" $40 \mathrm{~N} / \mathrm{cm}^{2}$ (equivalent to $4 \mathrm{~kg} / \mathrm{cm}^{2}$ weight force). ${ }^{4}$ This method has produced questionable inter-examiner reliability ${ }^{21-23}$ although this problem has been partially improved by the use of the algometer. ${ }^{23-25}$ However, there remains the problem that $19 \%$ of patients with at least 11 tender points may not have fibromyalgia syndrome. Additionally, tender points don't correlate well with other measures of illness activity, such as the fibromyalgia impact questionnaire. ${ }^{26}$ As a result of such diagnostic difficulties require further study to clarify the diagnosis of fibromyalgia syndrome.

\section{Symptom intensity scale: A new diagnostic tool}

The symptom intensity scale (SIS), a relatively new diagnostic tool, offers to assess both regional pain and fatigue in a patient. It can be used to establish the diagnosis of fibromyalgia syndrome and measure its severity in daily clinical practice without the need to count tender points. ${ }^{27}$ The SIS questionnaire consists of two parts: a list of 19 anatomical areas (jaws, chest, abdomen, forearms, upper legs, lower legs, upper arms, upper back, hips, shoulders, neck, low back) in which the patient is asked if he or she feels pain (the total number of affirmative answers being the regional pain scale [RPS] score), and a visual analog scale in which the patient makes a mark somewhere along a $10 \mathrm{~cm}$ line to indicate how tired he or she feels. Subsequently, the clinician measures the position of the mark from the left end of the line with a ruler. According to the survey criteria, a diagnosis of fibromyalgia can be established if the RPS score is 8 points or higher and the fatigue visual analog scale score is $6 \mathrm{~cm}$ or greater. (A score of $5.0 \mathrm{~cm}$ or greater on the fatigue visual analog scale is probably consistent with a diagnosis of fibromyalgia syndrome.) The SIS score is calculated according to the following formula:

(Fatigue visual analog scale $+\underline{\text { regional pain scale score) }}$ 2

2

A score $\geq 5.75$ is diagnostic for FM and differentiates fibromyalgia syndrome from other rheumatic conditions. ${ }^{27}$

Katz and colleagues compared ACR criteria, survey criteria and clinician diagnosis. They suggested that clinical diagnosis, ACR and survey criteria were moderately concordant
( $72 \%-75 \%)$ and addressed a common pool of symptoms and physical findings. They also suggested the survey method had the advantage as it did not require physical examination. ${ }^{28}$

\section{Imaging techniques} Functional MRI (fMRI)

fMRI is a noninvasive brain imaging technique that relies on changes in the relative concentration of oxygenated to deoxygenated hemoglobin within the brain. In response to neural activity, oxygenated blood flow is increased within the local brain area. This causes a decrease in the concentration of deoxygenated hemoglobin. Since deoxygenated hemoglobin is paramagnetic, this in turn causes a change in the magnetic property of the tissue. ${ }^{29}$

In a study by Gracely and colleagues ${ }^{30}$ of 16 fibromyalgia patients with 16 matched controls, both sets were exposed to painful pressures during the fMRI experiment. The authors found increased neural activations (ie, increases in the blood oxygenation level dependent signal) in FM patients, compared to the pain-free controls, when stimuli of equal pressure were administered.

At the present time, functional brain imaging in FM has revealed the following insights. 1) FM patients differ from healthy controls in baseline levels of neural activity, specifically in the caudate nucleus. 2) administration of a noxious pressure or heat stimulus results in changes in brain activity consistent with the verbal reports of patients' pain intensity. ${ }^{19}$

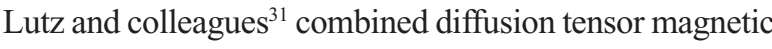
resonance imaging (DT-MRI) and voxel-based morphometry analyses of MRI to study patients with fibromyalgia syndrome to determine micro-structural and volume changes in the central neuronal networks involved in the sensory discriminative and affective-motivational characteristics of pain, anxiety, memory, and regulation of the stress response. Lutz and colleagues found decreases in gray matter volume, in the postcentral gyri, amygdalae, hippocampi, superior frontal gyri, and anterior cingulate gyri. They recognized that increased pain intensity scores were correlated with changes in DT-MRI measurements in the right superior frontal gyrus and increased fatigue was correlated with changes in the left superior frontal and left anterior cingulate gyrus, self-perceived physical impairment was correlated with changes in the left postcentral gyrus. ${ }^{31}$ They suggested that DT-MRI may serve as an additional diagnostic technique in FM and probably other dysfunctional pain syndromes.

\section{Magnetic resonance spectroscopy}

Magnetic resonance (MR) spectroscopy obtains spectra of multiple selected regions and determines the ratio of 
concentrations of metabolites such as N-acetyl-aspartate, creatine, choline, lactate, glucose and glutamate. Abnormalities in the levels of these metabolites are related to a number of pathological changes in brain tissue. ${ }^{19}$ In a recent study, to test the levels of these metabolites, in patients with FM, proton MR spectroscopy (H-MR spectroscopy) was used. It was suggested that there were baseline differences in the variability of the relative concentrations of brain metabolites, between patients with FM and healthy controls, in the right dorsolateral prefrontal cortex. Significant correlations between metabolite ratios and clinical and experimental pain parameters in patients with FM were also observed. ${ }^{32}$

\section{Single photon emission computed tomography (SPECT) and positron emission tomography (PET)}

Mountz ${ }^{33}$ used SPECT to evaluate baseline levels of regional cerebral blood flow (rCBF) in 10 patients with fibromyalgia and in seven healthy control subjects. In this initial study, patients received infusions of approximately $25 \mathrm{mCi}$ of ${ }^{99 m}$ Tc-HMPAO, a radioactive tracer that facilitates the imaging of rCBF. Results from this early study suggested that patients with FM had lower rCBF (suggesting lower neural activity) than healthy control subjects during a quiescent resting state. Reduced neural activity was found both in the right and left thalamus and in the right and left caudate nucleus. ${ }^{33}$

Kwiatek and colleagues ${ }^{34}$ used SPECT to assess resting rCBF in 17 patients with FM and in 22 healthy control subjects. These investigators observed decreased $\mathrm{rCBF}$ in the right thalamus, the inferior pontine tegmentum and near the right lentiform nucleus but, unlike the Mountz study, no decreases in either the left thalamus or in the caudate nuclei were noted. ${ }^{34}$

In a further study Gur and colleagues ${ }^{35}$ studied 19 young women with fibromyalgia and 20 healthy women, they also evaluated differences in $\mathrm{rCBF}$ between subject using SPECT. This study indicated a significant increase in rCBF of the caudate nuclei, a reduction in the pons, and some cortical region activity.

Adiguzel and colleagues used SPECT imaging to assess changes in $\mathrm{rCBF}$ following administration of amitriptyline in 14 fibromyalgia patients. After three months of treatment with amitriptyline, they noted increases in $\mathrm{rCBF}$ in thalamus bilaterally and the basal ganglia. ${ }^{36}$ This study is important as it compares rCBF in both the diagnosis of FM and in evaluating its treatment.

PET has been used in a few studies related to fibromyalgia. Wood and colleagues used PET to indicate that attenuated dopaminergic activity may be playing a role in pain transmission in fibromyalgia. ${ }^{29,37}$

Developments in novel imaging methods promises to increase our knowledge of the mechanisms that initiate and maintain FM, and may improve both diagnosis and treatment strategies.

\section{Treatment}

FM is a complex syndrome associated with significant functional and quality-of-life impairments. There is emerging evidence that fibromyalgia is associated with aberrant central nervous system processing of pain. ${ }^{38}$ Current treatments for fibromyalgia include medical, self-management and alternative therapies. Although recommendations (eg, European League Against Rheumatism [EULAR] and American Pain Society [APS]) for FM management have been published, a universally accepted treatment algorhythm or approach is often lacking. ${ }^{39-41}$

\section{Pharmacologic treatment}

\section{Antidepressants}

\section{Amitriptyline}

Amitriptyline is the most widely prescribed pharmacologic agent for treatment of $\mathrm{FM}^{42}$ and has consistently been found to alleviate FM symptoms. ${ }^{17}$ A large number of randomized clinical trials (RCTs) have demonstrated that clinically important improvement occurs in $25 \%-45 \%$ of FM patients given this drug. ${ }^{43-45}$ Amitriptyline was significantly better than placebo or than naproxen, $500 \mathrm{mg}$ twice daily, in pain reduction. ${ }^{46}$ One trial showed that when amitriptyline and fluoxetine were taken together, they were twice as effective as when either was taken alone. ${ }^{47}$ In general, pooled analyses demonstrate that the improvement with tricyclics was mild for fatigue and moderate for pain, sleep and overall well-being. The doses of tricyclics have been low, and most studies have been of short duration, such as 6-12 weeks. The doses of amitriptyline have been $25-50 \mathrm{mg}$, usually given as a single bedtime dose. ${ }^{48}$

\section{Cyclobenzaprine}

Cyclobenzaprine shares its tricyclic structure with amitriptyline and nortriptyline but does not function as an antidepressant. Instead, cyclobenzaprine acts at the brain stem to induce skeletal muscle relaxation. ${ }^{49}$ The idea that muscle spasm may play a role in fibromyalgia pain (despite electromyographic studies showing no evidence of spasm) led to investigations of cyclobenzaprine. ${ }^{44,50}$ Short-term (12-week) studies suggest that 10-40 mg per day of cyclobenzaprine reduces fibromyalgia pain and sleep disturbance. ${ }^{44,50}$ 


\section{Fluoxetine}

There is moderate evidence that the selective serotonin reuptake inhibitor (SSRI) fluoxetine is effective in FM. In one study of 42 patients with fibromyalgia, there was no significant benefit of FM administering fluoxetine (20 mg/day) when compared with placebo over a six-week period. ${ }^{51}$ However, a flexible placebo-controlled dose study of fluoxetine ( $<80 \mathrm{mg} /$ day) demonstrated significant efficacy in 60 women with fibromyalgia ${ }^{52}$ improvement was noted on a fibromyalgia impact questionnaire (FIQ) total score as well as subscores for pain, fatigue, and depression. Pain in tender points and total myalgic scores were not significantly improved. There was no difference in the measures of mood disturbances in the two groups and the effect of fluoxetine on pain was still significant after adjustment for change in depression score. ${ }^{53}$

\section{Citalopram}

Citalopram was used by Norregaard and colleagues ${ }^{54}$ to study its effect on a SSRI, in a placebo-controlled study of FM patients. The results demostrated there was no improvement in the patients who had received citalopram, when compared to the patients who had received placebo, of pain or other main symptoms such as; depression scores, fatigue or insomnia, after eight weeks of treatment.

In a study by Anderberg and colleagues, ${ }^{55}$ FM patients had 30-40 mg citalopram/day for four months. In the global judgment of improvements, no significant differences occurred between the citalopram and placebo groups. However, in a more detailed analysis of the patients who completed four months of treatment there were benefits in some areas. Regarding pain, there was a significant reduction of pain scores after two months of treatment in the patients receiving citalopram compared to the patients receiving placebo. However the difference diminished at the end of the trial. The FIQ showed improvement at four months. ${ }^{55}$ This study also assessed depressive symptoms, which improved in the citalopram group after one month and increased further over the duration of the trial

\section{Venlafaxine}

Venlafaxine is a generic serotonin and norepinephrine reuptake inhibitor (SNRI) that has efficacy in fibromyalgia management at a dosage of $75 \mathrm{mg}$ per day, and is a reasonable alternative for patients who cannot afford branded SNRIs. ${ }^{56}$ It significantly improved pain, fatigue, sleep quality, morning stiffness, depression, anxiety and patient global assessment of fibromyalgia in a small, open label clinical trial. ${ }^{57}$

\section{Reboxetine}

Reboxetine, a SNRI, has resulted in an increase of interest in the catecholamine pathway for the treatment of chronic pain. Double-blind, placebo-controlled studies indicate that as an antidepressant, reboxetine is more effective than placebo and similar in efficacy to other SSRIs and tricyclic antidepressants in reducing depressive symptoms, with a relatively benign side effect profile and may help stimulate physical activity and vitality. ${ }^{58}$

\section{Dopamine-related agents}

\section{Sibutramine}

Sibutramine, a serotonin/noradrenaline/dopamine reuptake inhibitor reduces presynaptic dopamine metabolism in FM, as demonstrated by positron emission tomography, and supports a disruption of dopaminergic neurotransmission involved in the pathophysiology of FM. ${ }^{37}$ In addition, it has been reported that patients with FM have an abnormal dopamine response to pain. ${ }^{59}$ Sibutramine has been reported to improve pain, sleep and fatigue in patients with FM in a pilot retrospective study; when sibutramine was stopped, FM symptoms returned within 3-7 days. ${ }^{60}$ Further studies with sibutramine are required to determine the value of such a combined pharmacological profile in the treatment of FM. ${ }^{61}$

\section{Pramipexole}

Pramipexole, a second-generation dopamine agonist developed for the treatment of Parkinson's disease was tested in patients with fibromyalgia in a 14-week, single center, randomized, placebo-controlled study in which pramipexole was added on to existing pharmacological and nonpharmacological therapies. ${ }^{62}$ The rationale for testing a dopamine D3 agonist in fibromyalgia is based on evidence that excessive adrenergic arousal may fragment sleep, and enhancement of dopaminergic neurotransmission at the D3 receptors in the mesolimbic hippocampus may reduce expression of arousal and improve sleep. Compared with the placebo group, those patients receiving pramipexole titrated over 12 weeks to $4.5 \mathrm{mg}$ every evening had gradual and significant improvement in pain, fatigue, function, and global status. ${ }^{63}$ The mechanism by which pramipexole improved the symptoms of fibromyalgia is unclear.

\section{$\mathrm{N}$-methyl-D-aspartate (NMDA) receptor antagonists}

\section{Ketamine}

Ketamine is a powerful high-affinity NMDA receptor antagonist was initially developed as an anesthetic. NMDA receptors may play a role in the nervous system reorganization 
thought to be involved in maintaining chronic pain, and its blockade can relieve pain in patients with FM. Two randomized, controlled trials involving 46 patients fulfilling the 1990 ACR classification criteria for FM showed that ketamine increased endurance and reduced pain intensity, tenderness at trigger points, referred pain, temporal summation, muscular hyperalgesia, and muscle pain at rest. ${ }^{64}$ Both studies suggested the presence of central sensitization in FM, that tender points are areas of secondary hyperalgesia, and that the relief of these symptoms by ketamine indicated a reduction in central sensitization. However, the cognitive side effects of NMDA receptor blockade may limit the use of NMDA in FM therapy.

\section{Memantine}

Memantine is an amantadine derivative that has been used to treat Parkinson's disease, spasticity, convulsions, vascular dementia, and Alzheimer's disease with an excellent clinical safety record for over 20 years. While decreased NMDA receptor affinity contributes to memantine's safety and efficacy as a neuroprotective agent, it also renders it less effective than high-affinity antagonists (eg, ketamine) in chronic pain management. ${ }^{65,66}$ Memantine may also show increased efficacy in the treatment of FM-associated chronic pain. Kim and colleagues ${ }^{67}$ reported an increased expression of NMDA receptor subunit 2D in the skin of FM patients with fibromyalgia, which could be indicative of a more generalized increase of the receptor in other peripheral nerves. Memantine may also suppress neuronal excitability and confers neuroprotection in a manner similar to pregabalin. ${ }^{68}$

\section{Atypical antipsychotics Olanzapine}

Olanzapine is a new "atypical" neuroleptic that has been effective for the treatment of many pain conditions, such as cancer pain, ${ }^{69}$ headache, ${ }^{70}$ and rheumatoid arthritis. ${ }^{71}$ Kiser and colleagues ${ }^{72}$ described two fibromyalgia patients who benefited from treatment with the atypical neuroleptic olanzapine when other medications have failed. ${ }^{73}$

\section{Ziprasidone}

Ziprasidone is a second-generation antipsychotic with potent 5-HT1A and 5-HT1B agonistic properties, a capacity, which has been linked to potential anxiolytic activity. ${ }^{74}$ In one study, ziprasidone was administered to 32 fibromyalgia patients at a dose of $20 \mathrm{mg} /$ day, subsequently adjusted according to clinical response and tolerability. It was noted that the conditions of stiffness, anxiety and sadness improved significantly but some side effects were observed like sleep disturbances, headache, tremor, and rigidity so the authors suggested that it could be tried on patients who are markedly anxious and/or depressed..$^{75}$

\section{Antiepileptics \\ Lacosamide}

Lacosamide (LCM) is a third-generation antiepileptic drug. The drug does not mimic the effects as an allosteric modulator of gamma-aminohydroxybutyrate (GABA) A receptor currents. ${ }^{76}$ Lacosamide selectively enhances sodium channel slow inactivation with no effect on fast inactivation. ${ }^{77}$ The drug displays affinity for the glycine strychnine-insensitive recognition site of the NMDA receptor complex, ${ }^{76}$ and allosterically blocks NMDA receptors with a specific action on receptors containing the NR2B subunit. ${ }^{78} \mathrm{LCM}$ is considered for monotherapy for partial-onset seizures and in patients in migraine prophylaxis or with fibromyalgia syndrome..$^{79,80}$

\section{Zonisamide}

Zonisamide (ZNS), a sulphonamide derivative, is a newgeneration anticonvulsant with multiple potential mechanisms that contribute to its antiepileptic efficacy and may also explain its currently incompletely assessed utility for nonseizure disorders such as headaches, neuropathic pain, and weight loss. The assessment of LCM and ZNS in patients with FM will provide insight into the potential of sodium channels as therapeutic targets in this condition. ${ }^{79}$

\section{Cannabinoids}

The endocannabinoid system shares several similarities with the opioid system. ${ }^{81}$ The cannabinoid receptor CB1 and opioid receptors are both found in similar areas of the nervous system involved in pain control, including the periaqueductal gray matter, rostral ventromedial medulla, and the spinal cord. ${ }^{82}$ Besides the similarities with the opioid system, cannabinoids have also been shown to inhibit prostaglandin $\mathrm{E}_{2}$ synthesis, ${ }^{83}$ and have an anti-inflammatory effect twice as great as hydrocortisone and 20 times that of aspirin. ${ }^{84,85}$

\section{Nabilone}

Nabilone is currently approved for the management of nausea and vomiting during chemotherapy. Other known action of cannabinoids including inhibition of prostaglandin $\mathrm{E}_{2}$ synthesis. ${ }^{83}$ Experimental increases in endorphins ${ }^{86}$ and the regulation of substance $P$ and enkephalin mRNA levels in the basal ganglia ${ }^{87}$ could all contribute to less pain experienced in the nabilone-treated patients. Research into 
oral cannabinoid use in the management of chronic and neuropathic pain has been encouraging. ${ }^{85,88}$ Skrabek and colleagues randomized patients into placebo and nabilone receiving groups. After four weeks of treatment patients who received nabilone experienced significant improvements in clinical pain, measured on a visual analog scale, FIQ score and the 10 point anxiety scale of the FIQ. After the wash-out period at the end of the trial all improvements were lost in nabilone group. ${ }^{85}$

\section{Alpha2-delta ligands Gabapentin}

Gabapentin is a GABA analogue that was originally developed for the treatment of epilepsy. The release of neurotransmitters that play a role in pain processing, such as glutamate and substance $\mathrm{P}$, are regulated by calcium influx into nerve terminals within the nociceptive pathways. ${ }^{89,90}$ The relevant sites of action include voltage-gated ion channels (ie, sodium and calcium channels), ligand-gated ion channels, the excitatory receptors for glutamate and NMDA, and the inhibitory receptors for GABA and glycine. ${ }^{91}$ Block of the presynaptic calcium channels by ligands of the $\alpha 2 \delta$ subunit of that channel (eg, gabapentin, pregabalin) will decrease the neurotransmitter release and attenuate abnormal hyperexcitability of neuronal networks such as that associated with chronic pain. ${ }^{41}$

In the gabapentin in fibromyalgia treatment (GIFT) study, an investigator-initiated, National Institutes of Health-funded study, gabapentin in patient-optimized doses between 1200 and $2400 \mathrm{mg}$ /day was compared with placebo over 12 weeks. ${ }^{92}$ The primary outcome, was the measure of pain as estimated by the brief pain inventory (BPI) average pain severity score. Patients treated with gabapentin (median dose $1800 \mathrm{mg}$ /day) had significantly greater improvement in pain severity than patients treated with placebo $(P<0.015)$. Gabapentin compared with placebo also significantly improved the BPI average pain interference score, the FIQ total score, the clinical global impression of severity, and the patient global impression of improvement. There was also improvement in sleep and vitality. ${ }^{92}$ Some patients though may have gabapentin associated dose-dependent dizziness and somnolence. ${ }^{92}$ Tolerance improves if patients are started on lower doses with incremental increases to the optimal dose. The severity of these adverse effects is generally mild with few discontinuations in clinical trials; however, these and other adverse events, including weight gain and peripheral edema, may limit the utility of these drugs in some patients. ${ }^{93}$

\section{Other pharmacologic medications}

\section{Tropisetron}

Tropisetron is a 5-hydroxytriptamine 3 (5HT3) serotonin antagonist. The presence of 5HT3 receptors on both the inhibitory dorsal horn interneurons and the primary afferent fibers that relay nociceptive information from peripheral nociceptives to the dorsal horn may explain the pro- and antinociceptive effects of 5-HT3 receptor blockade. ${ }^{63}$ In a randomized, placebo-controlled, double blind study patients with FM assessed the efficacy of tropisetron at doses $5 \mathrm{mg}$, $10 \mathrm{mg}, 15 \mathrm{mg}$ per day in a 10-day period. Patients who received $5 \mathrm{mg}$ and $10 \mathrm{mg}$ per day had significant reduction in pain. The effects of a dose of $15 \mathrm{mg}$ per day were not different from placebo. ${ }^{94}$ The mechanism by which 5 HT3 receptor antagonism reduces FM-associated pain and other symptoms are not understood, although these benefits may be secondary to reduced substance P release. ${ }^{95}$

\section{Tegaserod}

Tegaserod, a potent partial agonist of 5-hydroxytryptamine-4 receptors, has been used for the treatment of female irritable bowel syndrome (IBS) patients with constipation (IBS-C). It was shown to improve significantly symptoms of IBS-C within the first week of use. ${ }^{96}$ In a study the effect of tegaserod on signs and symptoms of FM in patients treated by this agent, in addition to improvement in IBS status after one month of tegaserod treatment, it was noted that a significant improvement in the general status of the patients, with improvement in their ability to perform daily tasks, and a significant decrease in anxiety and depression scores, together with a suppression of the number of tender points and the intensity of pain while palpating tender points. ${ }^{97}$

\section{Sodium oxybate}

Sodium oxybate is the sodium salt of gamma hydroxybutyrate (GHB), an endogenous short-chain fatty acid, and is used for the oral administration of exogenous GHB. ${ }^{98-100}$ It is likely that the supraphysiological concentrations induced by exogenous administration lead to qualitatively different neuronal actions from those produced by endogenous GHB. There is evidence suggesting that GHB plays a role as a neuromodulator/neurotransmitter. Sodium oxybate, in narcolepsy has shown dose-related effects on various properties of sleep. ${ }^{98}$ A preliminary four-week, double-blind, placebocontrolled crossover trial of 24 woman with FM suggested that sodium oxybate reduced symptoms of pain and fatigue, decreased tender point index, and increased slow-wave sleep and decreased alpha intrusion on polysomnography. ${ }^{99}$ 
Despite the results GHB is associated with likelihood of abuse. ${ }^{101}$ The most frequently reported adverse events included dose-related headache, nausea, dizziness, and somnolence.

\section{Modafinil}

Modafinil, unlike amphetamines, is well tolerated, with less peripheral hemodynamic alterations combined with low abuse and tolerance sequelae. It also improves vigilance in sleep-deprived patients. ${ }^{102}$ The mechanism by which modafinil might be helpful in the treatment of the fatigue in FM remains unknown. Experimentally, it activates nondopaminergic neurons in contrast with the amphetamines and methylphenidate that exert a significant effect on dopaminergic neurons. ${ }^{103,104}$

\section{Metilphenidate}

Metilphenidate has not been specifically studied as a treatment for fibromyalgia, however, it is the most commonly used stimulant in fibromyalgia therapy, owing to its low cost and the lack of insurance restrictions on its use. Psychostimulants could potentially be very helpful in fibromyalgia patients with 'fibrofog', as it can be considered analogous to adult attention deficit/hyper activity disorder and treated similarly. ${ }^{105}$

\section{Growth hormone}

Growth hormone (GH) is a polypeptide hormone secreted naturally by the anterior pituitary gland that stimulates cell growth and reproduction. There is some evidence of functional GH deficiency, expressed as low insulin-like growth factor 1 (IGF-1) serum levels, in a subset of fibromyalgia patients. ${ }^{106}$ There is a marked decrease in spontaneous integrated GH secretion. ${ }^{107} \mathrm{GH}$ deficiency in adults has been associated with symptoms that are similar to those described by patients with fibromyalgia: low energy, ${ }^{108}$ reduced exercise capacity, ${ }^{109}$ muscle weakness, cold intolerance, ${ }^{108}$ impaired cognition, ${ }^{110}$ dysthymia, ${ }^{108}$ and it was theorized that suboptimal levels may be a factor in the impaired resolution of muscle micro-trauma in fibromyalgia. ${ }^{111,112}$

A nine-month study of injectable recombinant human growth hormone in patients with low IGF levels at entry showed an improvement in FM symptoms as assessed by the FIQ total and tender point score. ${ }^{112}$ However, enthusiasm for this approach has been dampened by the appearance of adverse effects, the need for frequent injections, and high costs.

\section{Tramadol}

Tramadol is a centrally acting analgesic that is useful in the treatment of many pain disorders, including neuropathic pain and fibromyalgia. ${ }^{113,114}$ Tramadol has a unique mechanism of action that combines $\mu$-opioid activity with inhibition of serotonin/norepinephrine re-uptake. ${ }^{115}$ One or two tramadolparacetamol $(37.5 \mathrm{mg} / 325 \mathrm{mg})$ combination tablets taken four times daily can substantially lessen pain, stiffness, and work interference in patients with fibromyalgia. ${ }^{116} \mathrm{Common}$ adverse effects of this treatment are nausea, pruritis, and constipation.

\section{Anti-Inflammatory medications}

Anti-inflammatory medications have not been effective in the treatment of FM. Prednisone $20 \mathrm{mg}$ /day was no better than placebo. ${ }^{117}$ Nonsteroidal anti-inflammatory drugs (NSAIDs), including naproxen and ibuprofen, were not effective in FM, although they may have a synergistic effect when combined with medications active on the CNS. ${ }^{118}$ They are more likely to be helpful when fibromyalgia is present with associated pain disorders such as osteoarthritis.

\section{Pyridostigmine (PYD)}

Pyridostigmine is a parasympathomimetic and a reversible cholinesterase inhibitor. Treatment of FM patients with GH has been reported to be of some clinical benefit ${ }^{112}$ but GH is seldom prescribed because of its high costs and concerns regarding its long-term usage. ${ }^{119} \mathrm{GH}$ secretion in FM patients can be acutely increased by the use of PYD in combination with exercise. ${ }^{120}$ Jones and colleagues randomized their study participants to one of the following four groups: PYD plus exercise, PYD plus diet recall but no exercise, placebo plus exercise, and placebo plus diet recall but no exercise. The researchers suggested that neither the combination of PYD plus supervised exercise nor either treatment alone yielded improvement in most FM symptoms. However, PYD did improve anxiety and sleep, and exercise improved fatigue and fitness. They speculated that PYD might have improved vagal tone, thus benefiting sleep and anxiety; they also offered a further study. ${ }^{121}$

\section{Melatonin}

Melatonin has multiple actions including modulation of the sleep/wake cycle and benzodiazepine-like effects. ${ }^{122}$ Thus, melatonin administration improves sleep and rest, and decreases anxiety derived from sleeplessness. Additionally, melatonin also synchronizes neurotransmitter circadian rhythms including those of c-aminobutyric acid, benzodiazepine, dopamine, and glutamate. ${ }^{122,123}$ Also, melatonin has antistress properties and influences the HPA axis, which may account for some of its effects in FM. The actions of melatonin in terms of its ability to enhance mitochondrial bioenergetics ${ }^{124}$ may be pertinent to its beneficial effects in 
these patients. While reduced levels of melatonin have been reported in FM women, ${ }^{125,126}$ alterations in its circadian rhythm seem not to be a primary cause of FM.

\section{Approved medications}

Until early 2009 , only two drugs were approved by the US Food and Drug Administration (FDA) for the treatment of fibromyalgia: pregabalin, approved in June 2007 and duloxetine, approved in June 2008, on January 14, 2009, milnacipran was approved by the FDA for the management of FM. ${ }^{127}$ All three drugs have shown similar efficacy in pain management, ${ }^{128}$ but their abilities to manage other fibromyalgia symptoms are not the same. Their different pharmacodynamic and safety profiles, often make one a better initial choice than the others for an individual patient. ${ }^{129}$

\section{Pregabalin}

Pregabalin, like gabapentin, is an alpha-2delta-subunit ligand that exhibits anti-hyperalgesic, anxiolytic and anticonvulsant properties. ${ }^{90}$ Pregabalin's binding affinity for the alpha-2-delta subunit is six times higher than that of gabapentin, rendering pregabalin more clinically effective at lower doses. ${ }^{130}$ VeraLlonch and colleagues ${ }^{131}$ also suggest that pregabalin $(375 \mathrm{mg}$ / day) may provide better analgesic outcomes than gabapentin (1200 mg/day and $1800 \mathrm{mg} /$ day) over a 12-week period. This increased efficacy, as well as its favorable pharmacokinetic profile, renders pregabalin the preferred anticonvulsant adjuvant analgesic for chronic pain treatment. ${ }^{130} \mathrm{In}$ two randomized controlled trials (of 8 and 14 weeks, respectively) involving patients with FM, pregabalin significantly reduced the pain score and improved sleep and fatigue demonstrating efficacy against the three major symptoms of the condition. ${ }^{132,133}$ Although significantly more patients had $\geq 50 \%$ improvement in pain in the pregabalin than in the placebo group, this level of benefit was in a limited (up to 30\%) number of subjects. When $\geq 30 \%$ decrease in pain scores was determined, the number of responders only increased up to $50 \%$. A sixmonth double-blind, placebo-controlled trial demonstrated durability of the effects of pregabalin on pain, fatigue and sleep disturbance with an onset of effects within one week of treatment. ${ }^{134}$ Pregabalin significantly delayed the time to loss of therapeutic response, with $68 \%$ of patients maintaining therapeutic response at the end of the trial.

\section{Duloxetine and milnacipran}

The prevailing theory is that decreased serotinergic and noradrenergic activity leads to a decrease in activity via descending analgesic pathways, which in turn leads to pain as well as diffuse hyperalgesia and allodynia seen in fibromyalgia and a number of related conditions. ${ }^{29}$ For that reason selective SNRIs such as duloxetine and milnacipram demonstrate the greatest promise. Similar to pregabalin, they reduce not only pain, the primary symptom of FM, but also improve other symptom domains, and some aspects of function and global assessments. ${ }^{135}$

Duloxetine is an antidepressant, but is also effective in neuropathic pain independent of its effects on mood. It is a selective serotonin and norepinephrine reuptake inhibitor that is relatively balanced in its affinity for both serotonin and norepinephrine reuptake inhibition. A randomized, doubleblind, placebo controlled trial has evaluated duloxetine in patients with FM. ${ }^{136}$ In the initial study, men and women stratified for the presence of current major depression were treated with duloxetine $60 \mathrm{mg}$ twice daily compared with placebo. ${ }^{136}$ Outcome measures were based on FIQ total and pain scores, patients treated with duloxetine had significant improvement in the FIQ total score, but not the pain score. Significantly more women treated with duloxetine $(30 \%)$ than placebo (16\%), however, had more than $50 \%$ reduction in the FIQ pain score. ${ }^{137}$ Duloxetine-treated male patients failed to improve significantly.

Similar to duloxetine, milnacipran is a well-characterized small molecule that acts as a selective reuptake inhibitor of both serotonin and noradrenaline, ${ }^{138}$ but it is unique in its preference for norepinephrine reuptake inhibition and also binds NMDA receptors. Because of a higher affinity for the norepinephrine transporter than does duloxetine, milnacipran may be better for patients with severe fatigue and/or cognitive dysfunction (the so-called fibrofog). ${ }^{139}$ The FDA's approval of milnacipran was based on the results from two US-based phase III clinical efficacy trials - one of 15 weeks' and the other of 27 weeks' duration. In the 15 -week study, ${ }^{140}$ a significantly greater proportion of patients who received milnacipran (either $100 \mathrm{mg}$ or $200 \mathrm{mg}$ daily) than those who received placebo met the composite criteria for pain response and syndrome response. In some patients, a significant reduction in pain was seen as early as week 1 , and persisted to the end of the study. Other significant improvements for both the $100 \mathrm{mg}$ and $200 \mathrm{mg}$ groups were seen in indices of total impact FIQ, disability and fatigue. In addition, the $200 \mathrm{mg}$ dose led to significant improvements in short-form, 36-question health survey (SF-36) mental component scores and Beck Depression Inventory scores.

In the 27 -week study ${ }^{141}$ significantly more patients in the milnacipran treatment groups (100 $\mathrm{mg}$ or $200 \mathrm{mg}$ daily) than in the placebo group met the composite criteria for 
pain response and syndrome response at three months. At the 27-week end point, however, only the $200 \mathrm{mg}$ milnacipran group had significantly higher pain response rates than the placebo group, and neither milnacipran group had significantly higher syndrome response. Furthermore, cognition was significantly improved at both 15 and 27 weeks in the $200 \mathrm{mg}$ group. ${ }^{142}$

\section{Physical therapies}

\section{Transcutaneous electrical nerve stimulation}

Transcutaneous electrical nerve stimulation has been attempted and shown to be of little benefit to FM patients. It is more appropriate for localized pain versus the diffuse, generalized pain typically associated with fibromyalgia; this limits its usefulness in the treatment of the disease. ${ }^{143}$

\section{Ultrasound}

Ultrasound therapy has achieved recognition as a suitable method in physical medicine in treatment of acute and chronic musculoskeletal disorders. ${ }^{144}$ Experimental studies have shown that it is possible to heat deeper structures, such as joints, muscle, and bone, with ultrasound. ${ }^{145}$ It was suggested that combined therapy with pulsed ultrasound and interferential current, acting as an electrodiagnostic tool and as modality of physical therapy, provides an effective pain management, with consequent sleep improvement in FM. ${ }^{17,146,147}$

\section{Low level laser}

The exact mechanism of pain reduction by low level laser therapy is not completely understood. While underlying mechanism is unknown, it has been demonstrated in animal studies that laser therapy results in a selective reduction of $\mathrm{A} \beta$ and $\mathrm{C}$ fiber activity. ${ }^{148}$ Anti-inflammatory effects have been demonstrated both in vitro ${ }^{149}$ and in vivo ${ }^{150}$ and reduction of interstitial fluid at the site of inflammation has been described. ${ }^{151}$ It has also been suggested that low level laser therapy has effects on peripheral nerve stimulation and microcirculation regulation, interrupting the pain mechanism and thereby providing analgesia. ${ }^{152}$ In some experimental studies pain thresholds have been shown to increase owing to laser application. ${ }^{153}$ Analgesia may also occur due to the release of endogenous opioids following laser stimulation. ${ }^{151,155}$

Gur and colleagues ${ }^{156}$ previously carried out a randomized, single-blind and placebo-controlled study to evaluate the efficacy of $904 \mathrm{~nm}$ gallium arsenide (GaAs) low energy laser therapy in $40 \mathrm{FM}$ patients. ${ }^{156}$ It was found that there was no significant difference between the two groups with respect to all parameters before therapy whereas a significant difference was observed in parameters as pain, muscle spasm, morning stiffness and tender point numbers in favor of laser group after therapy. The authors suggest that laser therapy is an effective treatment of these parameters in FM patients and suggest that this therapy method is a safe and effective treatment. Gur and colleagues also carried out a randomized, single blind, and placebo-controlled study to compare the effectiveness of low energy laser therapy and low-dose (10 mg/day) amitriptyline therapy on clinical symptoms and quality of life in 50 patients with FM. In this study the authors concluded that both low dose amitriptyline and low level laser therapy is effective in reducing the clinical symptoms of FM and increasing quality of life (QoL). They conclude that such therapy is also a safe and effective treatment in the patients with FM. ${ }^{17,157}$

\section{Exercise}

Exercise, muscle strength, and endurance have been shown to be lower in patients with FM than healthy age-matched controls. ${ }^{158}$ A cycle is established, that activity produces micro trauma, increased local pain and generalized pain, so the patients decrease their activity level. Thus, one of the rationales for the exercise interventions in patients with FM is to break the cycle of deconditioning. ${ }^{159} \mathrm{~A}$ better muscular blood flow and less susceptibility to muscular micro trauma, as a result of regular training might improve pain in FM. As many fibromyalgia symptoms are also associated with deconditioning, the effect of various types of exercise, including aerobic dance, stationary cycling, and aerobic walking, have been evaluated. ${ }^{160,161}$ Cardiovascular exercise appears to be the most effective form of exercise (as compared to flexibility ${ }^{162}$ and relaxation ${ }^{163}$ exercises) in which fibromyalgia patients can participate. ${ }^{6}$ These studies suggest that aerobic exercise three times a week can reduce tender point tenderness. Overall pain may also decrease, although sleep and level of fatigue are likely to be unaffected.

\section{Magnetotherapy}

Magnetotherapy treatment of FM symptoms using static or pulsed magnet fields attached to the surface of the body has been also evaluated. Magnetotherapy can produce positive changes in the immunological condition of the patient, such as vasodilatation of the arterial part of capillaries, analgesia and anti-inflammatory action. Lena and Friol ${ }^{164}$ carried out a nonrandomized study with two groups of 25 FM patients. To one of these a pharmacologically conventional treatment was administered for 10 days. The second group completed 10 sessions of magnetotherapy using a magnetic bed, with 
solenoid placed in the dorsal region of the patient in prone position. At the end of the treatment, both groups had reduced tender points score, an improvement which lasted for 25 days. However, a greater improvement was observed in the pharmacological group. ${ }^{165}$

\section{Acupuncture}

Acupuncture is a treatment in traditional Chinese medicine with more than 2500 years of history for use in chronic pain and has been suggested for use in fibromyalgia. ${ }^{166}$ According to traditional Chinese medicine, fibromyalgia is caused by dysfunction of the liver, spleen, and kidney that interrupts or depletes the body's internal energy and blood flow, resulting in clinical symptoms. ${ }^{167,168}$

The National Institute of Health Consensus Conference on Aupuncture concluded that acupuncture may be useful as an adjunct or alternative treatment for FM. However, two recent, randomized, controlled trials found that acupuncture was no better than control interventions in the reduction of pain associated with FM. ${ }^{169}$

\section{Hyperbaric oxygen therapy}

Hyperbaric oxygen therapy (HBO) therapy has been used worldwide for the past 30 years to treat many diseases, including conditions caused by local hypoxia or ischemia. ${ }^{170} \mathrm{HBO}$ therapy involves breathing $100 \%$ oxygen via an endotracheal tube, mask or hood in a pressure chamber at pressures higher than 1 atmosphere absolute (ATA). The aim of HBO therapy in patients with FM is to reduce muscle hypoxia and increase levels of high-energy phosphate. Yildiz and colleagues ${ }^{171}$ carried out a randomized study exposing a group of $26 \mathrm{FM}$ patients to once daily 90-minute sessions of hyperbaric treatment at 2.4 atmospheres, five days a week for three weeks duration. A second group $(n=24)$ were administered air at 1 atmosphere and acted as control group. After receiving treatment, the hyperbaric group showed a significant improvement in tender points scores, pain threshold and pain severity. ${ }^{171}$

\section{Hydrotherapy}

Hydrotherapy affects muscular tone, joint mobility, and pain intensity by thermal and hydromechanical stimuli, which cause analgesia in the nerve endings that increases the pain threshold, thus resolving the muscular spasms. ${ }^{172}$ Moreover, a peripheral vasodilatation takes place, as well as an increase in the tendon extensibility, which benefits the conjunctive tissues. This helps to improve muscular ischemia and reduce the algesic mediators in $\mathrm{FM}^{173}$ Another prophylactic property of hydrotherapy is based on the concentration of elements and mineral compounds like carbon dioxide, calcium, magnesium, lithium, and sulphate, which are dissolved in water and can be absorbed through the skin, providing healing effects in several body organs and circulatory system, reducing muscular spasms, pain sensitivity, and increasing joint mobility, as well as peripheral circulation. ${ }^{174}$

During a randomized controlled trial, Buskila and colleagues examined the effects of sulphur bath balneotherapy on 48 patients with $\mathrm{FM} .{ }^{175}$ Subjects were randomly assigned to receive daily sulphur baths lasting 20 minutes with water from the Dead Sea, or no treatment, over a 10-day period. Blinded assessments revealed that although both groups improved on almost all areas measured, including physical functioning, tender point count, tenderness threshold, pain, fatigue, stiffness and anxiety measured using visual analog scales. The improvements were particularly remarkable in the treatment group and lasted for a minimum of three months.

\section{Osteopathic and chiropractic manipulation}

Osteopathic and chiropractic manipulation are treatment approaches that utilize joint manipulation. These techniques are intended to reduce pain, enhance muscle strength and joint mobility, provide proprioceptive training, and limit further joint and muscle damage. ${ }^{176} \mathrm{~A}$ common criticism of these techniques is that although they may be effective in reducing pain and increasing mobility, the effects may be short-lived. Chiropractic and osteopathy have become popular in the treatment of acute conditions, though there is little scientific evidence regarding their effectiveness in chronic conditions. ${ }^{177}$

In a study by Gamber and colleagues, ${ }^{178} 24$ patients with FM were randomly assigned to one of four treatment groups: manipulation, manipulation and teaching, moist heat, or a control group (standard medical care). Gamber and colleagues found significant improvements in pain, activities of daily living and chronic pain attributes in the manipulation treatment groups. However the small sample size and lack of follow-up data make it difficult to form definitive conclusions. Thus the evidence for the success of chiropractic and osteopathic intervention is insufficient, additional, larger randomized controlled trials are warranted to resolve its efficacy. ${ }^{177}$

\section{Electromyographic biofeedback training}

Electromyographic biofeedback training teaches an individual to become aware of processes and sensations in the body that are not normally apparent and with the use of special equipment bringing them under conscious control. An individual is hooked up to a biofeedback instrument which 
measures such physiological variables as skin temperature and heart rate. These measurements are then relayed back to the patient in real time to alter the body functions being measured. Since the equipment is designed to detect minute changes in the body functions being measured, the patients' effort to affect these processes is instantly reinforced by the display of these measurements, no matter how small and the patient is further encouraged to bring these processes into conscious awareness and control. Over time, the goal is to be able to influence these sensations and process without the aid of the biofeedback instruments. ${ }^{179}$

\section{Cognitive behavioral therapy}

Cognitive behavioural therapy (CBT) attempts to change physiological responses by manipulating cognitive reasoning and is intended to help patients feel that they are in control of their condition. This includes decreasing feelings of helplessness, reorganizing negative thoughts leading to pain and developing strategies for handling pain. ${ }^{180} \mathrm{~A}$ metaanalysis of CBT in chronic pain patients drew the conclusion that this form of therapy is indeed effective in this patient population. ${ }^{181}$ However, in a prospective study comparing a group that received intensive cognitive intervention with a control group that received less structured group discussions about pain and coping, the efficacy of this treatment did not significantly differ between the two groups. ${ }^{182}$

\section{Miscellaneous agents}

\section{S-Adenosyl-L-methionine}

S-adenosyl-L-methionine (SAMe), administered as a salt, is a naturally occurring active derivative of methionine present in all body tissue. Over the past 25 years, antidepressant, analgesic, and anti-inflammatory properties of SAMe have been identified. In the past 10 years, its role in the treatment of fibromyalgia has been evaluated in several small, shortduration, double-blind studies. A significant improvement of symptoms, including depression, pain, and the number of tender points, has been reported with oral, intravenous, and intramuscular administration of SAMe. ${ }^{183}$

\section{Botanical oils}

A single randomized, controlled, investigator-blinded study assessed pine oil and valerian on pain, sleep, and tender point count in patients with FM. ${ }^{184}$ Subjects were randomized into one of three whirlbath treatments, each given a total of 10 times (three times per week): valerian bath $(n=12)$, pine oil bath $(n=7)$, or plain water bath $(n=11)$. Valerian baths were associated with improved sleep, pine oil baths with increased sensitivity to pain in certain body areas, and plain water baths appeared to reduce pain intensity. However, both valerian and pine oil baths improved well-being.

\section{Chlorella pyrenoidosa}

Chlorella pyrenoidosa is a species of unicellular fresh water green algae rich in proteins, minerals and vitamins. Dietary supplementation with Chlorella pyrenoidosa has been associated with symptom relief in FM in two studies by the same research group. In the first study, an uncontrolled open-label trial, ${ }^{185}$ subjects with FM supplemented their diets with $10 \mathrm{~g}$ of Chlorella and $100 \mathrm{ml}$ of Chlorella extract for 2 months. The mean number of tender points decreased significantly. ${ }^{186} \mathrm{~A}$ larger, well-designed randomized placebocontrolled, double-blinded crossover clinical trial of 37 FM subjects also observed a significant reduction in the number of tender points among the treatment group compared with a slight increase in placebo subjects in addition to a significant increase in functioning. ${ }^{187,188}$

\section{Surgical treatment}

Thimineur and colleagues studied 12 patients with FM who were treated for comorbid chronic daily headaches with peripheral stimulation in the cervical plexus (C2) region of the scalp. They studied headache severity, quality of life, and FM symptoms, particularly diffuse pain, fatigue, and depression. Twelve patients (nine females and three males; mean age 48 years) who met criteria for FM, with a comorbid headache disorder, were implanted with C2 area stimulation technique. The outcome was prospectively studied with standard evaluation tools at baseline, three and six months postimplant. They recorded that visual analog scale pain levels for FM-related pain decreased significantly at six months, chronic fatigue and depression as assessed by the Beck Depression Inventory and fatigue impact scale, overall quality of life as assessed by the Health Survey Short Form 36 (SF-36) were also improved. They suggested that C2 area scalp stimulation might diminish pain and related symptoms in patients with FM. ${ }^{189}$

\section{Conclusion}

ACR classification criteria includes tender point count which is central to FM, however, tender points and widespread pain alone do not wholly describe fibromyalgia-a disorder with comorbid symptoms. Patients may have enough and appropriate tender points and yet not have fibromyalgia. However; there are many treatment options for the effective management of this disease that require the identification of 
individual symptoms. These symptoms are not limited to pain and tender points. Sleep disorders, cognitive dysfunctions, fatigue, stiffness, depression are also the components of this syndrome. It may be suggested that, revised or new evaluating criteria may help developing new diagnostic methods. Although various pharmacological treatments have been studied for treating FM, no single drug or groups of drugs has proved to be useful in treating these patients. However, three drugs have recently been approved by the US FDA for the treatment of FM; pregabalin, duloxetine, milnacipran. Symptom based treatment for individual therapy with a multidisciplinary approach that includes both pharmacological and nonpharmacological strategies are recommended.

\section{Disclosures}

The authors report no conflicts of interest in this work.

\section{References}

1. Wolfe F, Smythe HA, Yunus MB, Bennett RM, Bombardier C, Goldenberg DL, et al. The American College of Rheumatology 1990 Criteria for the Classification of Fibromyalgia. Report of the Multicenter Criteria Committee. Arthritis Rheum. 1990;33:160-172.

2. Yunus M, Masi A, Aldag J. A controlled study of primary fibromyalgia syndrome: clinical features and associations with other functional syndromes. J Rheumatol. 1989;16(Suppl 19):62-71.

3. Fitzcharles MA, Boulos P. Inaccuracy in the diagnosis of fibromyalgia syndrome: analysis of referrals. Rheumatology (Oxford). 2003;42:263-267.

4. Clauw DJ, Crofford LJ. Chronic widespread pain and fibromyalgia: what we know, and what we need to know. Best Pract Res Clin Rheumatol. 2003;17:685-701.

5. Mease PJ, Arnold LM, Crofford LJ, et al. Identifying the clinical domains of fibromyalgia: contributions from clinician and patient delphi exercises. Arthritis Rheum. 2008;59:952-960.

6. Wolfe F, Ross K, Anderson J, et al. The prevalence and characteristics of fibromyalgia in the general population. Arthritis Rheum. 1995;38:19-28.

7. Buskila D, Pres J. Neuroendocrine mechanisms in fibromyalgia-chronic fatigue. Best Pract Res Clin Rheumatol. 2001;15(5):747-758.

8. Adler GK, Geenen R. Hypothalamic-pituitary-adrenal and autonomic nervous system functioning in fibromyalgia. Rheum Dis Clin N Am. 2005;31:187-202.

9. Weigent DA, Bradley LA, Blalock JE, Alarcon GS. Current concepts in the pathophysiology of abnormal pain perception in fibromyalgia. Am J Med Sci. 1998;315(6):405-412.

10. Henriksson KG. Fibromyalgia-from syndrome to disease. Overview of pathogenetic mechanisms. J Rehabil Med. 2003;(Suppl 41):89-94.

11. Buskila D, Pres J. Neuroendocrine mechanisms in fibromyalgia-chronic fatigue. Best Pract Res Clin Rheumatol. 2001;15(5):747-758.

12. Sörensen J, Graven-Nielsen T, Henriksson KG, Bengtsson M, ArendtNielsen L. Hiperexcitability in fibromyalgia. J Rheumatol. 1998;25: 152-155.

13. Staud R. Fibromyalgia pain: do we know the source? Curr Opin Rheumatol. 2004;16(2):157-163.

14. Staud R, Vierck CJ, Cannon RL, Mauderli AP, Price DD. Abnormal sensitization and temporal summation of second pain (windup) in patients with fibromyalgia syndrome. Pain. 2001;91:165-167.

15. Staud R, Cannon RC, Mauderli AP, Robinson ME, Price DD, Vierck CJ Jr. Temporal summation of pain from mechanical stimulation of muscle tissue in normal controls and subjects with fibromyalgia syndrome. Pain. 2003;102:87-95.
16. Price DD, Staud R, Robinson ME, Mauderli AP, Cannon R, Vierck CJ. Enhanced temporal summation of second pain and its central modulation in fibromyalgia patients. Pain. 2002;99:49-59.

17. Gur A, Oktayoglu P. Central nervous system abnormalities in fibromyalgia and chronic fatigue syndrome: new concepts in treatment. Curr Pharm Des. 2008;14(13):1274-1294.

18. Harden RN, Revivo G, Song S, et al. A critical analysis of the tender points in fibromyalgia. Pain Med. 2007;8(2):147-156.

19. Williams DA, Gracely RH. Biology and therapy of fibromyalgia. Functional magnetic resonance imaging findings in fibromyalgia. Arthritis Res Ther. 2006;8:224.

20. Tunks E, Crook J, Norman G, Kalaher S. Tender points in fibromyalgia. Pain. 1988;34:11-19.

21. Bohr T. Problems with myofascial pain syndrome and fibromyalgia syndrome. Neurology. 1996;46:593-597.

22. Cohen M, Quintner J. Fibromyalgia syndrome, a problem of tautology. Lancet. 1993;342:906-909.

23. Tunks E, McCain GA, Hart LE, et al. The reliability of examination for tenderness in patients with myofascial pain, chronic fibromyalgia and controls. J Rheumatol. 1995;22:944-952.

24. McCarthy DJ Jr, Gatter RA, Phelps P. A dolorimeter for quantification of articular tenderness. Arthritis Rheum. 1965;8:551-559.

25. Fischer AA. Pressure algometry over normal muscles. Standard values, validity and reproducibility of pressure threshold. Pain. 1987;30: 115-126.

26. McVeigh JG, Finch MB, Hurley DA, Basford JR, Sim J, Baxter GD. Tender point count and total myalgic score in fibromyalgia: changes over a 28 day period. Rheumatol Int. 2007;27:1011-1018.

27. Wilke SW. New developments in the diagnosis of fibromyalgia syndrome: Say goodbye to tender points? Cleve Clin J Med. 2009;76(6):345-352.

28. Katz RS, Wolfe F, Michaud K. Fibromyalgia diagnosis: a comparison of clinical, survey, and American College of Rheumatology criteria. Arthritis Rheum. 2006;54(1):169-176.

29. Harris RE, Clauw DJ. Newer treatments for fibromyalgia syndrome Ther Clin Risk Manag. 2008;4(6):1331-1342.

30. Gracely RH, Petzke F, Wolf JM, et al. Functional magnetic resonance imaging evidence of augmented pain processing in fibromyalgia. Arthritis Rheum. 2002;46:1333-1343.

31. Lutz J, Jäger L, de Quervain D, et al. White and gray matter abnormalities in the brain of patients with fibromyalgia: a diffusion-tensor and volumetric imaging study. Arthritis Rheum. 2008;58(12):3960-3969.

32. Petrou M, Harris RE, Foerster BR, et al. Proton MR spectroscopy in the evaluation of cerebral metabolism in patients with fibromyalgia: comparison with healthy controls and correlation with symptom severity. Am J Neuroradiol. 2008;29(5):913-918.

33. Mountz JM, Bradley LA, Modell JG, et al. Fibromyalgia in women. Abnormalities of regional cerebral blood flow in the thalamus and the caudate nucleus are associated with low pain threshold levels. Arthritis Rheum. 1995;38:926-938.

34. Kwiatek R, Barnden L, Tedman R, et al. Regional cerebral blood flow in fibromyalgia: single-photon-emission computed tomography evidence of reduction in the pontine tegmentum and thalami. Arthritis Rheum. 2000;43:2823-2833.

35. Gur A, Karakoc M, Erdogan S, Nas K, Cevik R, Sarac AJ. Regional cerebral blood flow and cytokines in young females with fibromyalgia. Clin Exp Rheumatol. 2002;20(6):753-760.

36. Adiguzel O, Kaptanoglu E, Turgut B, et al. The possible effect of clinical recovery on regional cerebral blood flow deficits in fibromyalgia: a prospective study with semiquantitative SPECT. South Med $J$. 2004;97:651-655.

37. Wood PB, Patterson JC 2nd, Sunderland JJ, Tainter KH, Glabus MF, Lilien DL. Reduced presynaptic dopamine activity in fibromyalgia syndrome demonstrated with positron emission tomography: a pilot study. J Pain. 2007;8(1):51-58.

38. Staud R. Evidence of involvement of central neural mechanisms in generating fibromyalgia pain. Curr Rheumatol Rep. 2002;4:299-305. 
39. Burckhardt DC, Goldenberg D, Crofford L, et al. Guideline for the management of fibromyalgia syndrome pain in adults and children. In: APS Clinical Practice Guidelines Series. No 4. Glenview, IL: American Pain Society; 2005.

40. Carville SF, Arendt-Nielsen S, Bliddal H, et al. EULAR evidence-based recommendations for the management of fibromyalgia syndrome. Ann Rheum Dis. 2008;67:536-541.

41. Lawson K. Treatment options and patient perspectives in the management of fibromyalgia: future trends. Neuropsychiatr Dis Treat. 2008;4(6):1059-1071.

42. Maurizio SJ, Rogers JL. Recognizing and treating fibromyalgia. Nurse Pract. 1997;22:18-33.

43. Carette S, McCain GA, Bell DA, Fam AG. Evaluation of amitriptyline in primary fibrositis. A doubleblind, placebo-controlled study. Arthritis Rheum. 1986;29:655-659.

44. Bennett RM, Gatter RA, Campbell SM, et al. A comparison of cyclobenzaprine and placebo in the management of fibrositis. A double-blind controlled study. Arthritis Rheum. 1988;31:1535-1542.

45. Tofferi JK, Jackson JL, O’Malley PG. Treatment of fibromyalgia with cyclobenzaprine: a meta-analysis. Arthritis Care Res. 2004;51:9-13.

46. Goldenberg DL, Felson DT, Dinerman H. A randomized, controlled trial of amitriptyline and naproxen in the treatment of patients with fibromyalgia. Arthritis Rheum. 1986;29(11):1371-1377.

47. Goldenberg DL, Mayskiy M, Mossey C, Ruthazar R, Schmid C. A randomized, double-blind crossover trial of fluoxetine and amitriptyline in the treatment of fibromyalgia. Arthritis Rheum. 1996;39:1852-1859.

48. Goldenberg DL. Pharmacological treatment of fibromyalgia and other chronic musculoskeletal pain. Best Pract Res Clin Rheumatol. 2007;21(3):499-511.

49. Share NN, McFarlane CS. Cyclobenzaprine: a novel centrally acting skeletal muscle relaxant. Neuropharmacology. 1975;14(9):675-684.

50. Quimby LG, Gratwick GM, Whitney CD, Block SR. A randomized trial of cyclobenzaprine for the treatment of fibromyalgia. J Rheumatol Suppl. 1989;19:140-143.

51. Wolfe F, Cathey MA, Hawley DJ. A double-blind placebo controlled trial of fluoxetine in fibromyalgia. Scand J Rheumatol. 1994;23:255-259.

52. Arnold LM, Hess EV, Hudson JI, Berno SE, Keck PE. A randomized, placebo-controlled, double-blind, flexibledose study of fluoxetine in the treatment of women with fibromyalgia. Am J Med. 2002;112:191-197.

53. Burckhardt C, Crofford L. Management of fibromyalgia syndrome. JAMA. 2004;292(19):2388-2395.

54. Norregaard J, Volkmann H, Danneskiold-Samsoe B. A randomized controlled trial of citalopram in the treatment of fibromyalgia. Pain. 1995;61(3):445-449.

55. Anderberg UM, Marteinsdottir I, von Knorring L. Citalopram in patients with fibromyalgia-a randomized, double-blind, placebo-controlled study. Eur J Pain. 2000;4:27-35.

56. Sayar K, Aksu G, Ak I, Tosun M. Venlafaxine treatment of fibromyalgia. Ann Pharmacother. 2003;11:1561-1565.

57. Dwight MM, Arnold LM, O'Brien H, Metzger R, Morris-Park E, Keck PE Jr. An open clinical trial of venlafaxine treatment of fibromyalgia. Psychosomatics. 1998;39:14-17.

58. Krell H, Cook IA, Abrams M, et al. Reboxetine yields symptomatic and functional improvement in unipolar depression. Scottsdale, AZ: Poster abstracts from the 41st Annual Meeting of the National Institutes of Mental Health's New Clinical Drug Evaluation Unit; 2001.

59. Wood PB, Schweinhardt P, Jaeger E, et al. Fibromyalgia patients show an abnormal dopamine response to pain. Eur J Neurosci. 2007;25: 3576-3582.

60. Palangio M, Flores JA, Joyal SV. Treatment of fibromyalgia with sibutramine hydrochloride monohydrate. Arthritis Rheum. 2002;46:2545-2546.

61. Lawson K. Pharmacological treatments of fibromyalgia: do complex conditions need complex therapies? Drug Discov Today. 2008;13(7-8): 333-340.

62. Holman AJ, Myers RR. A randomized, double-blind, placebocontrolled trial of pramipexole, a dopamine agonist, in patients with fibromyalgia receiving concomitant medications. Arthritis Rheum. 2005;52:2495-2505.
63. Arnold LM. Biology and therapy of fibromyalgia. New therapies in fibromyalgia. Arthritis Res Ther. 2006;8(4):212.

64. Hocking G, Cousins MJ. Ketamine in chronic pain management: an evidence-based review. Anesth Analg. 2003;97:1730-1739.

65. Nikolajsen L, Gottrup H, Kristensen AGD, Jensen TS. Memantine (a N-methyl-Daspartate receptor antagonist) in the treatment of neuropathic pain after amputation or surgery: a randomized, double-blinded, cross-over study. Anesth Analg. 2000;91:960-966.

66. Weinbroum AA, Rudick V, Paret G, Ben-Abraham R. The role of dextromethorphan in pain control. Can J Anaesth. 2000;47:585-596.

67. Kim SH, Jang TJ, Moon IS. Increased expression of N-methyl-Daspartate receptor subunit 2D in the skin of patients with fibromyalgia. J Rheumatol. 2006;33:785-788.

68. Recla JM, Sarantopoulos CD. Combined use of pregabalin and memantine in fibromyalgia syndrome treatment: a novel analgesic and neuroprotective strategy? Med Hypotheses. 2009;73(2):177-183.

69. Khojainova N, Santiago-Palma J, Kornick C, Breitbart W, Gonzales GR. Olanzapine in the management of cancer pain. J Pain Symptom Manage. 2002;23:346-350.

70. Silberstein SD, Peres MFP, Hopkins MM, Shechter AL, Young WB, Rozen TD. Olanzapine in the treatment of refractory migraine and chronic daily headache. Headache. 2002;42:515-518.

71. Gorski ED, Willis KC. Report of three case studies with olanzapine for chronic pain. J Pain. 2003;4:166-168.

72. Kiser R, Cohen HM, Freedenfeld RN, Jewell C, Fuchs PN. Olanzapine for the treatment of fibromyalgia symptoms. J Pain Symptom Manage. 2001;22:704-708

73. Freedenfeld RN, Murray M, Fuchs PN, Kiser RS. Decreased pain and improved quality of life in fibromyalgia patients treated with olanzapine, an atypical neuroleptic. Pain Pract. 2006;6(2):112-118.

74. Stahl SM, Shayegan DK. The psychopharmacology of ziprasidone: receptor-binding properties and real-world psychiatric practice. J Clin Psychiatry. 2003;64(9):6-12.

75. Calandre EP, Hidalgo J, Rico-Villademoros F. Use of ziprasidone in patients with fibromyalgia: a case series. Rheumatol Int. 2007;5:473-476.

76. Errington AC, Coyne L, Stöhr T, Selve N, Lees G. Seeking a mechanism of action for the novel anticonvulsant lacosamide. Neuropharmacology. 2006;50:1016-1029.

77. Errington AC, Stöhr T, Heers C, Lees G. The investigational anticonvulsant lacosamide selectively enhances slow inactivation of voltage-gated sodium channels. Mol Pharmacol. 2008;73:157-169.

78. Bialer M, Johannessen SI, Kupferberg HJ, Levy RH, Perucca E, Tomson T. Progress report on new antiepileptic drugs: a summary of the Eighth Eilat Conference (EILAT VIII). Epilepsy Res. 2007;73:1-52.

79. US National Institutes of Health. ClinicalTrials.gov. Available from: http://www.clinicaltrials.gov/. Accessed on October 10, 2009.

80. Luszczki JJ. Third-generation antiepileptic drugs: mechanisms of action, pharmacokinetics and interactions. Pharmacol Rep. 2009;61(2):197-216.

81. Corchero J, Manzanares J, Fuentes JA. Cannabinoid/opioid crosstalk in the central nervous system. Crit Rev Neurobiol. 2004;16:159-172.

82. Salio C, Fischer J, Franzoni MF, Mackie K, Kaneko T, Conrath M. CB1-canabinoid and mu-receptor co-localization on postsynaptic target in the rat dorsal horn. NeuroReport. 2001;12:3689-3692.

83. Burstein S, Levin E, Varanelli C. Prostoglandins and cannabis, II: Inhibition of biosynthesis by the naturally occurring cannabinoids. Biochem Pharmacol. 1973;22:2905-2910.

84. Evans FJ. Cannabinoids: The separation of central from peripheral effects on a structural basis. Planta Med. 1991;57:S60-S67.

85. Skrabek RQ, Galimova L, Ethans K, Perry D. Nabilone for the treatment of pain in fibromyalgia. J Pain. 2008;9(2):164-173.

86. Wiegant VM, Sweep CG, Nir I. Effect of acute administration of delta 1-tetrahydrocannabinol on beta-endorphin levels in plasma and brain tissue of the rat. Experientia. 1987;43:413-415.

87. Mailleux P, Vanderhaeghen JJ. Delta-9-tetrahydrocannabinol regulates substance P and enkephalin mRNAs levels in the caudate-putamen. Eur J Pharmacol. 1994;267:R1-R3. 
88. Ko G, Wine W. Chronic pain and cannabinoids: A survey study of current fibromyalgia treatment approaches together with an overview and case studies of a new "old" treatment approach. Pract Pain Manage. 2005:1-8.

89. Millan MJ. Descending control of pain. Prog Neurobiol. 2002;66: 355-474.

90. Dooley DJ, Taylor CP, Donevan S, et al. Ca2 ${ }^{+}$channel alpha2delta ligands: novel modulators of neurotransmission. Trends Pharmacol Sci. 2007;28:75-82.

91. Kranzler J, Gendreau J, Rao S. The psychopharmacology of fibromyalgia: a drug development perspective. Psychopharmacol Bull. 2002;36:165-213.

92. Arnold LM, Goldenberg DL, Stanford SB, et al. Gabapentin in the treatment of fibromyalgia: a randomized, double-blind, placebocontrolled, multicenter trial. Arthritis Rheum. 2007;56:1336-1344.

93. Crofford LJ. Pain management in fibromyalgia. Curr Opin Rheumatol. 2008;20(3):246-250.

94. Farber L, Stratz T, Bruckle W, et al. Efficacy and tolerability of tropisetron in primary fibromyalgia- a highly selective and competitive 5-HT3 receptor antagonist. Scand J Rheumatol. 2000;113:49-54.

95. Stratz T, Muller W. The use of 5-HT3 receptor antagonists in various rheumatic diseases-a clue to the mechanism of action of these agents in fibromyalgia? Scand J Rheumatol. 2000;113:66-71.

96. Evans BW, Clark WK, Moore DJ, Whorwell PJ. Tegaserod for the treatment of irritable bowel syndrome and chronic constipation. Cochrane Database Syst Rev. 2007;4:CD003960.

97. Reitblat T, Zamir D, Polishchuck I, Novochatko G, Malnick S, Kalichman L. Patients treated by tegaserod for irritable bowel syndrome with constipation showed significant improvement in fibromyalgia symptoms. A pilot study. Clin Rheumatol. 2009;28(9):1079-1082.

98. Pardi D, Black J. Gamma-hydroxybutyrate/sodium oxybate: neurobiology, and impact on sleep and wakefulness. CNS Drugs. 2006;20:993-1018.

99. Scharf MB, Baumann M, Berkowitz DV. The effects of sodium oxybate on clinical symptoms and sleep patterns in patients with fibromyalgia. J Rheumatol. 2003;30:1070-1074.

100. Sarzi-Puttini P, Buskila D, Carrabba M, Doria A, Atzeni F. Treatment strategy in fibromyalgia syndrome: where are we now? Semin Arthritis Rheum. 2008;37(6):353-365.

101. Griffiths RR, Johnson MW. Relative abuse liability of hypnotic drugs: A conceptual framework and algorithm for differentiating among compounds. J Clin Psychiatry. 2005;66(9):31-41.

102. Schwartz T, Rayancha S, Rashid A, Chlebowksi S, Chilton M, Morel M. Modafinil treatment for fatigue associated with fibromyalgia (concise reports) J Clin Rheumatol. 2007;13:52

103. Lin JS, Hou Y, Jouvet M. Potential brain neuronal targets for amphetamine-methylphenilate- and modafinil-induced wakefulness, evidenced by c-fos immunocytochemistry in the cat. Proc Natl Acad Sci U S A. 1996;93:14128-14133.

104. Pachas WN. Modafinil for the treatment of fatigue of fibromyalgia. J Clin Rheumatol. 2003;9(4):282-285.

105. Glass JM. Fibromyalgia and cognition. J Clin Psychiatry. 2008;69(2):20-24.

106. Bennett RM, Cook DM, Clark SR, Burckhardt CS, Campbell SM. Hypothalamic-pituitary-insulin-like growth factor-I axis dysfunction in patients with fibromyalgia. J Rheumatol. 1997;24:1384-1389.

107. Leal-Cerro A, Povedano J, Astorga R, et al. The growth hormone (GH)-releasing hormone-GH-insulin-like growth factor-1 axis in patients with fibromyalgia syndrome. J Clin Endocrinol Metab. 1999;84:3378-3381.

108. Cuneo RC, Salomon F, McGauley GA, Sönksen PH. The growth hormone deficiency syndrome in adults. Clin Endocrinol. 1992;37:387-397.

109. Cuneo RC, Salomon F, Wiles CM, et al. Growth hormone treatment in growth hormone-deficient adults. II. Effects on exercise performance. J Appl Physiol. 1991;70:695-700.

110. McGauley GA, Cuneo RC, Salomon F, So“nksen PH. Psychological well-being before and after growth hormone treatment in adults with growth hormone deficiency. Horm Res. 1990;33(Suppl 4):52-54.
111. Bennett RM. The contribution of muscle to the generation of fibromyalgia symptomatology. J Musculoskel Pain. 1996;4:35-59.

112. Bennett RM, Clark SC, Walczyk J. A randomized, double-blind, placebo-controlled study of growth hormone in the treatment of fibromyalgia. Am J Med. 1998;104(3):227-231.

113. Harati Y, Gooch C, Swenson M, et al. Maintenance of the longterm effectiveness of tramadol in treatment of the pain of diabetic neuropathy. J Diabetes Complications. 2000;14:65-70.

114. Russell IJ, Kamin M, Bennett RM, et al. Efficacy of tramadol in treatment of pain in fibromyalgia. J Clin Rheumatol. 2000;6:250-257.

115. Raffa RB, Friderichs E, Reimann W, et al. Opioid and nonopioid components independently contribute to the mechanism of action of tramadol, an 'atypical' opioid analgesic. J Pharmacol Exp Ther. 1992;260:275-285.

116. Bennett RM, et al. impact of fibromyalgia pain on health-related quality of life before and after treatment with tramadol/acetaminophen. Arthritis Rheum. 2005;53:519-527.

117. Clark S, Tindall E, Bennett RM. A double blind crossover trial of prednisone versus placebo in the treatment of fibrositis. J Rheumatol. 1985;12:980-983.

118. Goldenberg DL, Felson DT, Dinerman H. A randomized, controlled trial of amitriptyline and naproxen in the treatment of patients with fibromyalgia. Arthritis Rheum. 1986;29:1371-1377.

119. Ur E, Serri O, Legg K, Murphy LJ, Ezzat S. Canadian guidelines for the management of adult growth hormone deficiency. Clin Invest Med. 2006;29:83-90

120. Paiva ES, Deodhar A, Jones KD, Bennett R. Impaired growth hormone secretion in fibromyalgia patients: evidence for augmented hypothalamic somatostatin tone. Arthritis Rheum. 2002;46:1344-1350.

121. Jones KD, Burckhardt CS, Deodhar AA, Perrin NA, Hanson GC, Bennett RM. A six-month randomized controlled trial of exercise and pyridostigmine in the treatment of fibromyalgia. Arthritis Rheum. 2008;58(2):612-622.

122. Acuña-Castroviejo D, Escames G, Macias M, et al. Cell protective role of melatonin in the brain. J Pineal Res. 1995;19:57-63.

123. Khaldy H, León J, Escames G, et al. Circadian rhythm of dopamine and their metabolites in mouse striatum: effects of pinealectomy and melatonin replacement. Neuroendocrinology. 2002;75: 201-208

124. Acuña-Castroviejo D, Escames G, López LC, Hitos AB, León J. Melatonin and nitric oxide: two required antagonists for mitochondrial homeostasis. Endocrine. 2005;27(2):159-168.

125. Almay BG, Von Knorring L, Wetterberg L. Melatonin in serum and urine in patients with idiopathic pain syndromes. Psychiatr Res. 1987;22:179-191.

126. Acuna-Castroviejo D, Escames G, Reiter RJ. Melatonin therapy in fibromyalgia. J Pineal Res. 2006;40(1):98-99.

127. FDA Center for Drug Evaluation and Research. Savella (milnacipran) label information. January 8, 2009. Available from: http://www.fda gov/cder/foi/label/2009. Accessed on October 10, 2009.

128. Boomershine CS. First pregabalin and now duloxetine for fibromyalgia syndrome: closer to a brave new world? Nat Clin Pract Rheumatol. 2008;4:636-637.

129. Boomershine CS, Crofford LJ. A symptom-based approach to pharmacologic management of fibromyalgia. Nat Rev Rheumatol. 2009;5(4):191-199.

130. Gajraj NM. Pregabalin: its pharmacology and use in pain management. Anesth Analg. 2007;105:1805-1015.

131. Vera-Llonch M, Dukes E, Argoff C, Oster G. Analgesic outcomes in patients with painful diabetic neuropathy or post-herpetic neuralgia receiving pregabalin versus gabapentin. J Pain. 2005;6:S33.

132. Crofford LJ, Rowbotham MD, Mease PJ, et al. Pregabalin for the treatment of fibromylagia syndrome: Results of a randomized, double-blind, placebo-controlled trial. Arthritis Rheum. 2005;52:1264-1273.

133. Arnold L, Russell I, Diri E, et al. A 14-week, randomized, doubleblinded, placebo-controlled monotherapy trial of pregabalin in patients with fibromyalgia. J Pain. 2008;9(9):792-805. 
134. Crofford LJ, Mease PJ, Simpson SL, et al. Fibromyalgia relapse evaluation and efficacy for durability of meaningful relief (FREEDOM): a 6-month, double-blind, placebo-controlled trial with pregabalin. Pain. 2008;136(3):419-431.

135. Zareba G. New treatment options in the management of fibromyalgia: role of pregabalin. Neuropsychiatr Dis Treat. 2008;4(6):1193-1201.

136. Arnold LM, Lu Y, Crofford LJ, et al. A double-blind, multicenter trial comparing duloxetine with placebo in the treatment of fibromyalgia patients with or without major depressive disorder. Arthritis Rheum. 2004;50:2974-2984.

137. Arnold LM, Pritchett YL, D'Souza DN, et al. Duloxetine for the treatment of fibromyalgia in women: pooled results from two randomized, placebocontrolled clinical trials. J Womens Health (Larchmt). 2007;16:1145-1156

138. Gendreau RM, Mease PJ, Rao SR, Kranzler JD, Clauw DJ. Milnacipran: a potential new treatment of fibromyalgia. Arthritis Rheum. 2003;48:S616.

139. Stahl SM, Grady MM, Moret C, Briley M. SNRIs: their pharmacology, clinical efficacy, and tolerability in comparison with other classes of antidepressants. CNS Spectr. 2005;10:732-747.

140. Clauw DJ, Mease P, Palmer RH, Gendreau RM, Wang Y. Milnacipran for the treatment of fibromyalgia in adults: a 15-week, multicenter, randomized, double-blind, placebocontrolled, multiple-dose clinical trial. Clin Ther. 2008;30:1988-2004.

141. Mease PJ, Clauw DJ, Gendreau RM, et al. The efficacy and safety of milnacipran for treatment of fibromyalgia. A randomized, double-blind, placebocontrolled trial. J Rheumatol. 2009;36:398-409.

142. Bennett RM. Fibromyalgia: a new treatment option for fibromyalgia. Nat Rev Rheumatol. 2009;5(4):188-190.

143. Forseth KØ, Gran JT. Management of fibromyalgia: what are the best treatment choices? Drugs. 2002;62(4):577-592.

144. Gam AN, Warming S, Larsen LH, et al. Treatment of myofascial trigger points with ultrasound combined with massage and exercise-a randomized controlled trial. Pain. 1998;77(1):73-79.

145. Lehmann J, Delateur B, Warren C, Stonebridge J. Heating of joint structures by ultrasound. Arch Phys Med Rehabil. 1968;49(1): 28-30.

146. Gur A. Physical therapy modalities in management of fibromyalgia. Curr Pharm Des. 2006;12(1):29-35.

147. Almeida TF, Roizenblatt S, Benedito-Silva AA, Tufik S. The effect of combined therapy (ultrasound and interferential current) on pain and sleep in fibromyalgia. Pain. 2003;104(3):665-672.

148. Wassselmann U, Lin SF, Rymer WZ. Selective decrease of small sensory neurons in lumbar dorsal root ganglia labeled with horseradish peroxidase after ND: YAG laser irradiation of the tibial nerve in the rat. Exp Neurol. 1991;111(2):251-262.

149. Sattayut S, Hughes F, Bradley P. 820 nm Gallium Aluminium Arsenide laser modulation of a prostaglandin E2 production in interleukin 1 stimulated myoblasts. Laser Ther. 1999;11(2):88-95.

150. Campana VR, Moya M, Gavotto A, Juri H. The relative effects of He-Ne laser and meloxicam on experimentally induced inflammation. Laser Ther: 1999;11(1):36-42.

151. Nishida J, Satoh T, Satodate R. Histological evaluation of the effect of He Ne laser irradiation an the synovial membrane in rheumatoid arthritis. Japanese J Rheumatol. 1990;2:251-260.

152. Siebert W, Seichert N, Siebert B, Wirth CJ. What is the efficacy of soft and mid lasers in therapy of tendinopathies? A double-blind study. Arch Orthop Trauma Surg. 1987;106(6):358-363.

153. Olavi A, Pekka R, Pertti K, Pekka P. Effects of the infrared laser therapy at treated and non-treated trigger points. Acupunct Electrother Res. 1989;14(1):9-14.

154. Laasko EL, Cramond T, Richardson C, Galligan JP. Plasma ACTH and $\beta$-endorphin levels in response to low level laser therapy for myofascial trigger points. Laser Ther. 1994;6(3):133-142.

155. Pioro-Boisset M, Esdaile JM, Fitzcharles M. Alternative medicine use in fibromyalgia syndrome. Arthritis Care Res. 1996;9(1): $13-17$.
156. Gur A, Karakoç M, Nas K, Çevik R, Saraç AJ, Demir E. Efficacy of low power laser therapy in fibromiyalgia: a single-blind, placebo-controlled trial. Lasers Med Sci. 2002;17:57-61.

157. Gur A, Karakoç M, Nas K, Çevik R, Saraç AJ, Ataoğlu S. Effects of low power laser and low dose amitriptyline therapy on clinical symptoms and quality of life in fibromyalgia: a single-blind, placebo-controlled trial. Rheumatol Int. 2002;22: 188-193.

158. Mannerkorpi K, Burckhardt CS, Bjelle A. Physical performance characteristics of women with fibromyalgia. Arthritis Care Res. 1994; 7:123-129.

159. Bengtsson A, Henriksson KG, Larsson J. Muscle biopsy in primary fibromyalgia: light microscopical and histochemical findings. Scand J Rheumatol. 1986;15:1-6.

160. McCain GA, Bell DA, Mai FM, Halliday PD. A controlled study of the effects of a supervised cardiovascular fitness training program on the manifestations of primary fibromyalgia. Arthritis Rheum. 1988;31:1135-1141.

161. Nichols DS, Glenn TM. Effects of aerobic exercise on pain perception, affect, and level of disability in individuals with fibromyalgia. Phys Ther. 1994;74:327-332.

162. McCain G, Bell D, Mai F, et al. A controlled study of the effects of a supervised cardiovascular fitness training program on the manifestations of primary fibromyalgia. Arthritis Rheum. 1988;31(9): 1135-1141.

163. Martin L, Nutting A, MacIntosh BR, Edworthy SM, Butterwick D, Cook J. An exercise program in the treatment of fibromyalgia. JRheumatol. 1996;23:1050-1053.

164. Lena Fortuna R, Friol González JE. Fibromialgia y Magnetoterapia. Revista Cubana de Reumatología. 2002;4(1):56.

165. Sueiro Blanco F, Estévez Schwarz I, Ayán C, Cancela J, Martín V. Potential benefits of non-pharmacological therapies in fibromyalgia. Open Rheumatol J. 2008;2:1-6.

166. Holdcraft LC, Assefi N, Buchwald D. Complementary and alternative medicine in fibromyalgia and related syndromes. Best Pract Res Clin Rheumatol. 2003;17:667-683.

167. Singh BB, Wu WS, Hwang SH, et al. Effectiveness of acupuncture in the treatment of fibromyalgia. Altern Ther Health Med. 2006; 12:34-41.

168. Rooks DS. Fibromyalgia treatment update. Curr Opin Rheumatol. 2007;19(2):111-117.

169. Assefi NP, Sherman KJ, Jacobsen C, Goldberg J, Smith WR, Buchwald D. A randomized clinical trial of acupuncture compared with sham acupuncture in fibromyalgia. Ann Intern Med. 2005; 143(1):10-19.

170. Jain KK. Physical, physiological, and biochemical aspects of hyperbaric oxygenation. In: Jain KK, Neubauer R, Correa JG, Camporesi EM, editors. Textbook of Hyperbaric Medicine, 2nd ed. Seattle, WA: Hogrefe and Huber Publishers; 1996. p. 11-26.

171. Yildiz S, Kiralp MZ, Akin A, et al. A new treatment modality for fibromyalgia syndrome: hyperbaric oxygen therapy. J Int Med Res. 2004;32(3):263-267.

172. Curkovic B, Vitulic V, Babic-Naglic D, Durrigl T. The influence of heat and cold on the pain threshold in rheumatoid arthritis. Z Rheumatol. 1993;52:289-291.

173. Lehmann JE. Diathermy and superficial heat, laser and cold therapy. In: Kottke EJ, Lehmann JE, editors. Krusen's Handbook of Physical Medicine and Rehabilitation. Philadelphia, PA: Saunders; 1990.

174. Cimbiz A, Bayazit V, Hasan Hallaceli H, Ugur Cavlak U. The effect of combined therapy (spa and physical therapy) on pain in various chronic diseases. Complement Ther Med. 2005;13:244-250.

175. Buskila D, Abu-Shakra M, Neumann L, et al. Balneotherapy for fibromyalgia at the Dead Sea. Rheumatol Int. 2001;20:105-108.

176. Crofford LJ, Appleton BE. Complementary and alternative therapies for fibromyalgia. Curr Rheumatol Rep. 2001;3:147-156.

177. Adams N, Sim J. Rehabilitation approaches in fibromyalgia. Disabil Rehabil. 2005;27(12):711-723. 
178. Gamber RG, Shores JH, Russo DP, Jimenez C, Rubin BR. Osteopathic manipulative treatment in conjunction with medication relieves pain associated with fibromyalgia syndrome: Results of a randomized clinical pilot project. J Am Osteopath Assoc. 2002;102:321-325.

179. Pioro-Boisset M, Esdaile JM, Fitzcharles M. Alternative medicine use in fibromyalgia syndrome. Arthritis Care Res. 1996;9(1):13-17.

180. Keefe FJ, Caldwell DS. Cognitive behavioral control of arthritis pain. Med Clin North Am. 1997;81:277-290.

181. Morley S, Eccleston C, Williams A. Systematic review and metaanalysis of randomized controlled of cognitive behavior therapy and behavioral therapy for chronic pain in adults, excluding headache. Pain. 1999;80(1-2):1-13.

182. Vlaeyen JW, Teeken-Gruben NJ, Goossens ME, et al. Cognitiveeducational treatment of fibromyalgia: a randomized clinical trial. I. Clinical effects. J Rheumatol. 1996;23:1237-1245.

183. Jacobsen S, Danneskiold-Samsoe B, Andersen RB. Oral $\mathrm{S}$-adenosylmethionine in primary fibromyalgia. Double-blind clinical evaluation. Scand J Rheumatol. 1991;20:294-302.
184. Ammer K, Melnizky P. Medicinal baths for treatment of generalized fibromyalgia. Forsch Komplementarmed. 1999;6:80-85.

185. Abraham GE, Flechas ID. Management of fibromyalgia: a rationale for the use of magnesium and malic acid. J Nutr Med. 1992;3:49-59.

186. Merchant RE, Carmack CA, Wise CM. Nutritional supplementation with chlorella pyrenoidosa for patients with fibromyalgia syndrome: a pilot study. Phytother Res. 2000;14:167-173.

187. Merchant RE, Andre C. A review of recent clinical trials of the nutritional supplement Chlorella pyrenoidosa in the treatment of fibromyalgia, hypertension, and ulcerative colitis. Altern Ther Health Med. 2001;7:79-91.

188. Holdcraft LC, Assefi N, Buchwald D. Complementary and alternative medicine in fibromyalgia and related syndromes. Best Pract Res Clin Rheumatol. 2003;17(4):667-683.

189. Thimineur M, De Ridder D. C2 area neurostimulation: a surgical treatment for fibromyalgia. Pain Med. 2007;8(8):639-646.
Open Access Rheumatology Research and Reviews

\section{Publish your work in this journal}

Open Access Rheumatology Research and Reviews is an international, peer-reviewed, open access journal, publishing all aspects of clinical and experimental rheumatology in the clinic and laboratory including the following topics: Pathology, pathophysiology of rheumatologica diseases; Investigation, treatment and management of rheumatological

\section{Dovepress}

diseases; Clinical trials and novel pharmacological approaches for the treatment of rheumatological disorders. The manuscript management system is completely online and includes a very quick and fair peerreview system, which is all easy to use. Visit http://www.dovepress.com/ testimonials.php to read real quotes from published authors.

Submit your manuscript here: http://www.dovepress.com/open-access-rheumatology-research-and-reviews-journal 